\title{
ALTERAÇÕES FISIOLÓGICAS E ENZIMÁTICAS DURANTE A MATURAÇÃ̃O DE SEMENTES DE PIMENTA (Capsicum annuum L.) ${ }^{1}$
}

\author{
DEBORAH DE SOUZA VIDIGAL², DENISE CUNHA F. SANTOS DIAS ${ }^{3}$, EDILA VILELA DE REZENDE VON PINHO4, \\ LUIZ ANTÔNIO DOS SANTOS DIAS ${ }^{3}$
}

\begin{abstract}
RESUMO - O trabalho teve como objetivo avaliar as alterações fisiológicas e enzimáticas em sementes de pimenta, cv. Amarela Comprida, obtidas de frutos colhidos em diferentes estádios de maturação e submetidos ao armazenamento pós-colheita. Os frutos foram colhidos aos 40, 50, 60 e 70 dias após a antese (DAA) e submetidos ao armazenamento por 0, 3, 6, 9, 12 e 15 dias para, então, proceder à extração das sementes. A qualidade fisiológica das sementes foi avaliada pelos testes de germinação, primeira contagem de germinação, deterioração controlada e condutividade elétrica. Avaliaram-se, ainda, as alterações nos sistemas enzimáticos malato desigrogenase (MDH), álcool desidrogenase (ADH), superóxido dismutase (SOD) e peroxidase (PO). Melhores resultados de germinação e vigor e maior atividade de enzimas, envolvidas na respiração e proteção contra radicais livres, são observados em sementes obtidas de frutos colhidos a partir de 60 DAA, não sendo necessário o armazenamento destes após a colheita.
\end{abstract}

Termos para indexação: germinação, vigor, isoenzimas, maturidade.

\author{
PHYSIOLOGICAL AND ENZYMATIC CHANGES DURING PEPPER SEEDS \\ (Capsicum annuum L.) MATURATION
}

\begin{abstract}
Physiological and enzymatic changes in sweet pepper seeds obtained from fruits harvested at different maturation stages and submitted to post-harvest storage were assessed. Pepper fruits, 'Amarela Comprida' cultivar, were harvested at 40, 50, 60 and 70 days after anthesis (DAA) and stored for $0,3,6,9,12$ and 15 days before seed extraction. Seeds were evaluated by the germination, first count, controlled deterioration and electrical conductivity tests. Changes in the enzymatic systems malate desidrogenasis (MDH), alcohol desidrogenasis (ADH), superoxide dismutase (SOD) and peroxidase (PO) were also determined. Pepper seeds obtained from fruits harvested at 60 DAA presented better germination and vigor and higher activity of enzymes involved in respiration and protection against free radicals, and post-harvest storage of these fruits was not necessary.
\end{abstract}

Index terms: germination, vigor, isoenzyme, maturity.

${ }^{1}$ Submetido em 26/06/2008. Aceito para publicação em 28/10/2008. Parte da Dissertação de Mestrado do primeiro autor apresentada a UFV.

${ }^{2}$ Estudante de Pós-Graduação, Depto. de Fitotecnia, Universidade Federal de Viçosa, 36571-000 - Viçosa - MG. E-mail: dsvidigal@gmail.com
${ }^{3}$ Prof. Associado, Depto. de Fitotecnia, , Universidade Federal de Viçosa, 36571-000 - Viçosa - MG. E-mail: dcdias@ufv.br

${ }^{4}$ Prof. Associado, Depto. de Agricultura, Universidade Federal de Lavras, 37200-000 - Lavras - MG 


\section{INTRODUÇÃO}

Estudos relacionados à maturação e colheita das sementes são importantes, uma vez que estas alcançam sua qualidade máxima no campo. Tais conhecimentos são imprescindíveis, principalmente, no que se refere ao planejamento e definição da época ideal de colheita para minimizar os efeitos da deterioração das sementes provocados pela permanência prolongada no campo, além de aumentar a produtividade das sementes, visto que a colheita precoce poderá acarretar grande proporção de sementes imaturas.

Em espécies de crescimento indeterminado como a pimenta, onde o florescimento e frutificação são contínuos, são encontrados na mesma planta frutos em diferentes estádios de maturação, o que dificulta determinar a época em que ocorre a maturidade fisiológica das sementes e o momento ideal para a colheita dos frutos, visando obter o máximo rendimento em sementes de alto vigor.

Em espécies de frutos carnosos, alguns estudos têm demonstrado que, sementes mantidas por determinado período de tempo no fruto, após a colheita, dão continuidade ao processo de maturação atingindo níveis máximos de germinação e vigor (Sanchez et al., 1993; Barbedo et al., 1994; Vidigal et al., 2006 e Dias et al., 2006a). Logo, o armazenamento pós-colheita dos frutos antes da extração das sementes pode ser um aspecto vantajoso, pois permite colheros frutos precocemente evitando riscos com possíveis condições desfavoráveis (Barbedo et al., 1994). Também permite reduzir o número de colheitas, colhendo simultaneamente frutos em diversos estádios de maturação, extraindo-se imediatamente as sementes dos frutos maduros e submetendo os demais a período adequado de armazenamento. Durante este período, sementes ainda não totalmente maduras completariam sua maturação, enquanto aquelas já maduras teriam sua qualidade preservada por manterem-se em equilíbrio osmótico dentro do fruto, ou seja, com alto grau de umidade (Barbedo et al., 1994; Dias et al., 2006a).

Em geral, a qualidade da semente é máxima por ocasião da maturidade fisiológica, ou seja, quando o conteúdo de matéria seca é máximo (Nascimento et al., 2006); a partir daí, a germinação e o vigor geralmente declinam. Contudo, há controvérsias quanto à ocorrência da qualidade máxima das sementes durante o seu desenvolvimento, podendo não coincidir com o conteúdo máximo de massa seca. Em pimentão, Oliveira et al. (1999) verificaram que o máximo acúmulo de matéria seca foi alcançado antes da qualidade máxima da semente. Já para sementes de tomate, Dias et al. (2006b) verificaram que o acúmulo máximo de matéria seca ocorreu, em geral, depois da qualidade máxima da semente.

De acordo com Marcos Filho (2005), a deterioração é um processo determinado por uma série de alterações fisiológicas, bioquímicas, físicas e citológicas, com inicio a partir da maturidade fisiológica, que ocorre de maneira progressiva, determinando a queda da qualidade e culminando com a morte da semente. As principais alterações relacionadas ao processo de deterioração são degradação e inativação de enzimas (Copeland e McDonald, 2001), redução da atividade respiratória (Ferguson et al., 1990) e perda de integridade das membranas celulares (McDonald, 1999). Copeland e McDonald (2001) destacaram que para detectar o início da deterioração das sementes, as avaliações mais sensíveis são aquelas relacionadas à atividade de enzimas associadas à biossíntese em tecidos novos, uma vez que, com o processo de deterioração das sementes, as enzimas tornam-se menos eficientes para exercer sua atividade catalítica.

Assim, variações nos perfis de proteínas e de enzimas específicas, principalmente aquelas relacionadas ao processo respiratório e à peroxidação de lipídios e remoção de radicais livres, podem se constituir em ferramenta eficiente para monitorar as alterações bioquímicas resultantes da deterioração (Chauhan et al., 1985).

Os principais estudos referentes à maturação de sementes estão relacionados ao monitoramento das modificações fisiológicas que acontecem durante o processo, especialmente, conteúdo de massa seca, germinação e vigor. São escassas, portanto, informações referentes às alterações na atividade de enzimas durante o desenvolvimento e maturação das sementes. Diante do exposto acima, o presente trabalho teve como objetivo avaliar alterações fisiológicas e enzimáticas em sementes de pimenta colhidas em diferentes estádios de maturação e submetidas ao armazenamento pós-colheita dos frutos.

\section{MATERIAL E MÉTODOS}

O campo de produção de sementes foi instalado em área experimental denominada "Horta Nova" do Departamento de Fitotecnia da Universidade Federal de Viçosa (UFV), no período de fevereiro a julho de 2007. O município de Viçosa localiza-se na Zona da Mata de Minas Gerais, a 689,7 m de altitude e coordenadas geográficas $20^{\circ} 45^{\prime}$ de latitude Sul e $42^{\circ} 51^{\prime}$ de longitude Oeste (IBGE, 1991). As análises laboratoriais foram feitas no Laboratório de Pesquisa em Sementes da UFV e no Laboratório de Análise de Sementes da Universidade Federal de Lavras (UFLA).

Foram utilizadas sementes de pimenta (Capsicum 
annuum L.), variedade Amarela Comprida. Após a semeadura e obtenção das mudas em viveiro, estas foram transplantadas, aos 40 dias de idade, para o local definitivo. No campo, as plantas foram dispostas em espaçamento de $1,2 \times 0,8 \mathrm{~m}$ e o cultivo das plantas foi realizado conforme Filgueira (2005). As plantas foram tutoradas com o auxílio de estacas e a adubação foi feita de acordo com recomendações de Ribeiro et al. (1999). Durante a fase de florescimento, as flores foram etiquetadas diariamente, no dia da antese, até se obter número suficiente de frutos. Foram colhidos frutos aos 40, 50, 60 e 70 dias após a antese (DAA). Os frutos obtidos em cada época de colheita foram armazenados sob condição de ambiente $\left(25^{\circ} \mathrm{C}\right)$, em laboratório, por $0,3,6$, 9, 12 e 15 dias. Em seguida, as sementes foram extraídas dos frutos manualmente e lavadas em água corrente. Após a lavagem, foram colocadas para secar em condição de ambiente por período de tempo suficiente ( 2 a 3 dias) para atingir grau de umidade compatível para o armazenamento (aproximadamente 10\%). Após a secagem, as sementes foram tratadas com o produto comercial Captan 750 TS. 24 (3g produto/ $\mathrm{kg}$ de sementes), com exceção daquelas destinadas à realização do teste de condutividade elétrica. Em seguida, foram submetidas aos seguintes testes e determinações: Germinação - foram utilizadas quatro subamostras de 50 sementes distribuídas sobre duas folhas de papel toalha umedecidas com volume de solução de nitrato de potássio $\left(\mathrm{KNO}_{3}\right)$ 0,2\% equivalente a 2,5 vezes o peso do papel seco, em caixas gerbox. As caixas foram mantidas em germinador a $25{ }^{\circ} \mathrm{C}$. As avaliações foram feitas no décimo e décimo sétimo dias após a semeadura e os resultados expressos em percentagem de plântulas normais (Brasil, 1992). Primeira contagem de germinação - consistiu do registro da porcentagem de plântulas normais obtidas no décimo dia após a instalação do teste de germinação. Condutividade elétrica - foram utilizadas quatro subamostras de 50 sementes, com massas conhecidas, imersas em $25 \mathrm{~mL}$ de água destilada e mantidas em incubadora $\mathrm{BOD}$, a $25^{\circ} \mathrm{C}$, por 24 horas (Vidigal et al, 2008). Após esse período, a condutividade elétrica de cada solução foi determinada em condutivímetro, e os resultados expressos em $\mu \mathrm{S} . \mathrm{cm}^{-1} . \mathrm{g}^{-1}$ de sementes. Deterioração controlada - inicialmente, 350 sementes foram hidratadas, sobre papel toalha umedecido, pelo método da adição de água calculada (ISTA, 1995), até atingirem $24 \%$ de água. Em seguida, foram acondicionadas em sacos aluminizados, que foram hermeticamente fechados e mantidos por uma noite a $10{ }^{\circ} \mathrm{C}$. Decorrido este período, as embalagens contendo as sementes foram colocadas em banho-maria, a $45^{\circ} \mathrm{C}$, por 24 horas. Após este período, foram submetidas ao teste de germinação, conforme já descrito, avaliando-se a porcentagem de plântulas normais, aos 14 dias após a semeadura. Análise de isoenzimas - Para as avaliações bioquímicas foram usadas apenas sementes armazenadas por 0, 6 e 12 dias, extraídas de frutos colhidos aos 40, 50, 60 e 70 DAA. Duas amostras de sementes de cada tratamento foram maceradas em recipiente de porcelana contendo PVP (antioxidante) e nitrogênio líquido para evitar a desnaturação de proteínas pelo aquecimento. O pó obtido foi armazenado em freezer a $-81{ }^{\circ} \mathrm{C}$. Retiraram-se subamostras de $100 \mathrm{mg}$, nas quais foram adicionados o tampão de extração (Tris $\mathrm{HCl} 0,2 \mathrm{M} \mathrm{pH} \mathrm{8)} \mathrm{na} \mathrm{quantidade} \mathrm{de} \mathrm{2,5} \mathrm{vezes} \mathrm{o} \mathrm{peso} \mathrm{de}$ cada amostra e $0,1 \%$ de $\beta$-mercaptoetanol. O material foi colocado em refrigerador overnight e, depois, centrifugado a $14.000 \mathrm{rpm}$, por 30 minutos, a $4^{\circ} \mathrm{C}$. Foram aplicados $50 \mu \mathrm{L}$ do sobrenadante no gel e promovida a corrida eletroforética, por seis horas, a $120 \mathrm{~V}$. Os géis foram revelados para enzimas álcool desidrogenase (ADH), malato desidrogenase $(\mathrm{MDH})$, peroxidase (PO) e superóxido dismutase (SOD), segundo Alfenas (2006). Delineamento experimental e análise estatística - utilizou-se delineamento inteiramente casualizado, com quatro repetições, em esquema fatorial 4 x 6 , sendo 4 épocas de colheitas (40, 50, 60 e 70 DAA) e 6 períodos de armazenamento pós-colheita dos frutos $(0,3,6$, 9, 12 e 15 dias). As análises estatísticas foram processadas no Sistema SAS de Análise Estatística (SAS, 1989). Os valores obtidos para as variáveis foram submetidos a testes de normalidade e homogeneidade, que indicaram a não necessidade de transformação. As estimativas dos parâmetros de regressão foram analisadas pelo teste "t" a 5\% de probabilidade.

\section{RESULTADOS E DISCUSSÃO}

A germinação das sementes provenientes de frutos colhidos aos 40 DAA não armazenados e armazenados por três dias foi nula, sendo crescente a partir de seis dias de armazenamento pós-colheita dos frutos. No entanto, os valores obtidos foram relativamente baixos não ultrapassando $40 \%$ (Figura 1). A germinação das sementes oriundas de frutos colhidos aos 50 DAA foi crescente com o armazenamento destes por até 12 dias, decrescendo a partir daí. Por outro lado, o armazenamento pós-colheita de frutos com 60 e 70 dias de idade não promoveu aumento significativo na germinação das sementes, que se manteve praticamente estável até o final do período (15 dias). Também, para sementes de tomate, variedade Kadá, oriundas de frutos colhidos aos 40 DAA, à germinação foi nula nos frutos sem 
armazenamento e atingiu 97\% com o armazenamento por 12 dias (Vidigal et al., 2006). Sanchez et al. (1993) observaram que houve aumento na germinação de sementes de pimentão obtidas de frutos colhidos aos 30 DAA e armazenados por 14 dias, ocorrendo máxima germinação quando os frutos foram colhidos aos 50 DAA e armazenados por sete dias.
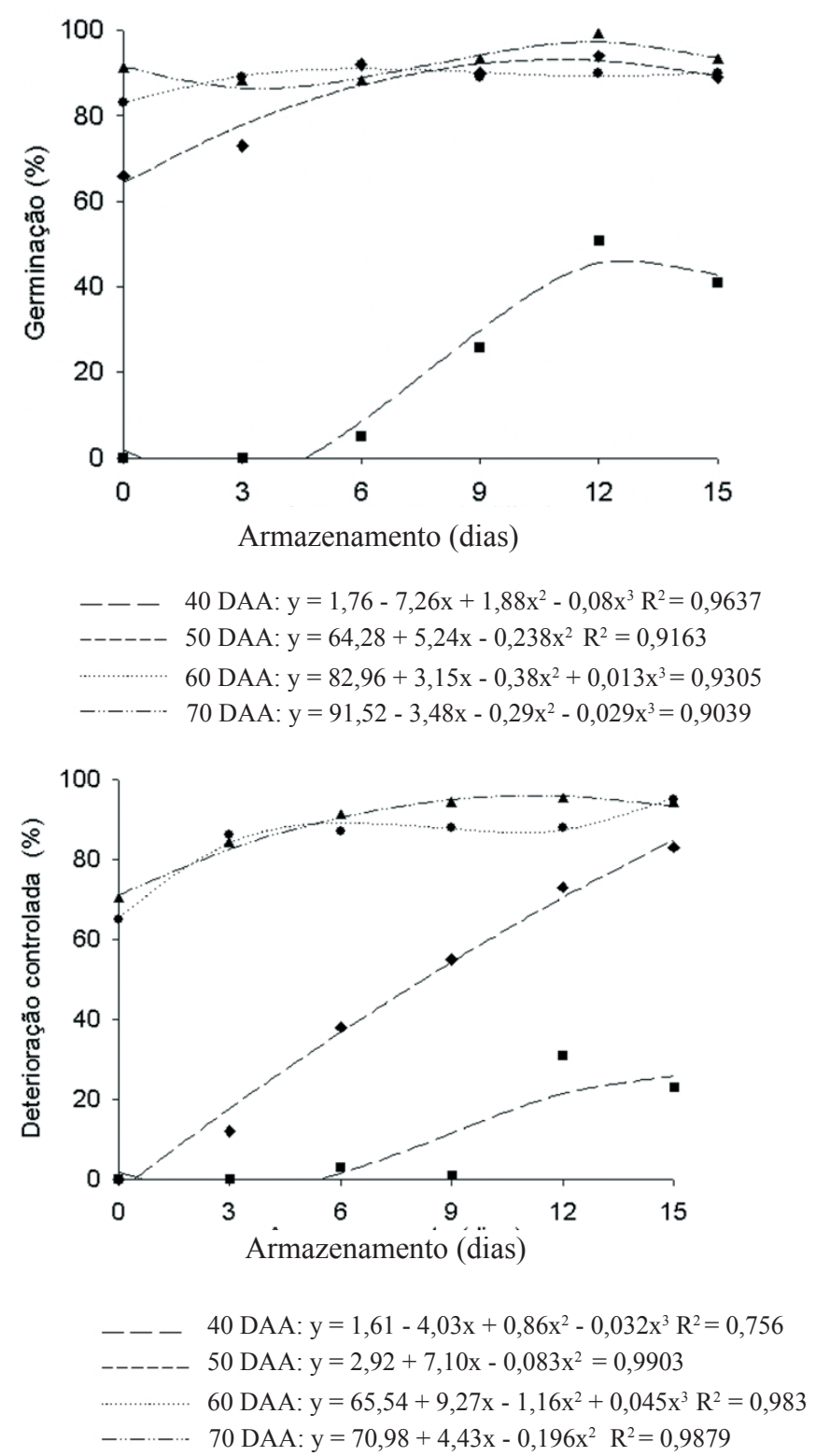

Por sua vez, Costa et al. (2006) registraram que mesmo o maior período de armazenamento (30 dias) não foi suficiente para que frutos de abóbora híbrida, com 20 ou 30 dias de idade, produzissem sementes de qualidade similar às obtidas de frutos com 50 e 60 dias, não submetidos ao armazenamento.
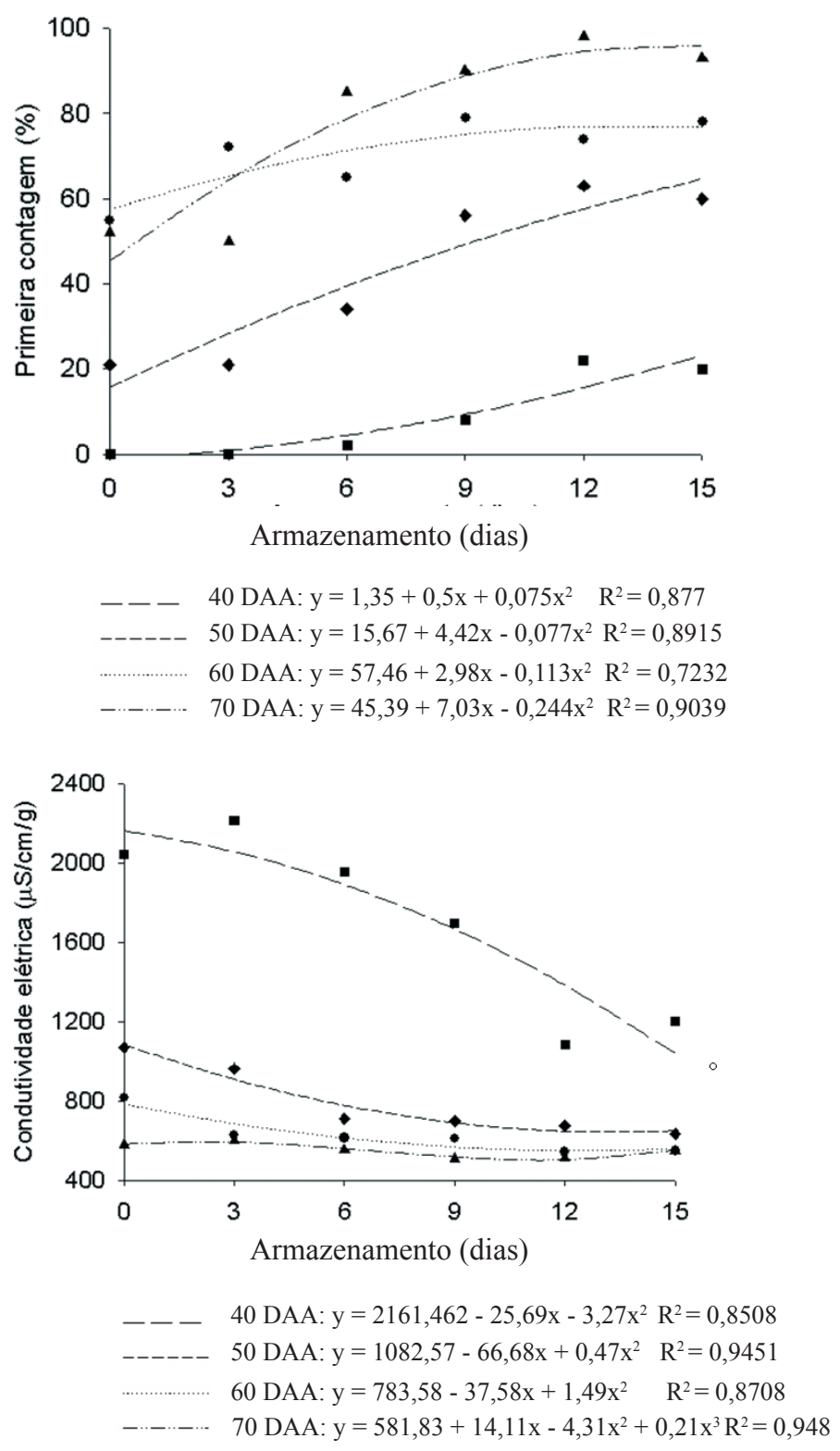

FIGURA 1. Plântulas normais (\%) obtidas nos testes de germinação (TG), primeira contagem de germinação (PC) e deterioração controlada (DC) e condutividade elétrica (CE) de sementes de pimenta extraídas de frutos colhidos aos 40, 50, 60 e 70 DAA e armazenados por 0, 3, 6, 9, 12 e 15 dias.

$\mathrm{O}$ vigor das sementes, avaliado pela primeira contagem da germinação e deterioração controlada (Figura 1), aumentou durante o armazenamento pós-colheita dos frutos para todas as épocas de colheita estudadas. Contudo, aos 40 DAA, o nível de vigor das sementes ainda era reduzido, mesmo após o armazenamento dos frutos. Nota-se, ainda, 
que o efeito do armazenamento pós-colheita dos frutos no vigor das sementes foi mais pronunciado para aqueles colhidos aos 50 DAA, uma vez que sementes obtidas de frutos colhidos nesta época e não armazenados tiveram baixo vigor, que aumentou, significativamente, até o $15^{\circ}$ dia de armazenamento pós-colheita. No entanto, não atingiram nível de vigor semelhante aos obtidos para sementes extraídas de frutos colhidos aos 60 e 70 DAA. Em geral, maior vigor foi observado para sementes obtidas de frutos colhidos nestas duas épocas. É importante ressaltar que o armazenamento de frutos com 70 dias de idade por, no mínimo, 9 dias, foi suficiente para elevar a germinação na primeira contagem de $52 \%$ (frutos sem armazenamento) para $90 \%$.

Houve redução nos valores de condutividade elétrica com o decorrer da maturação, indicando aumento no vigor das sementes (Figura 1). A condutividade elétrica de sementes obtidas de frutos com 40 dias de idade e não armazenados foi elevada, decrescendo gradativamente ao longo do armazenamento destes, porém apresentando valores sempre mais altos do que aqueles constatados para as sementes obtidas nas demais épocas de colheita. Assim, como constatado nos demais testes de vigor, menor condutividade, indicando maior vigor, foi obtida para sementes extraídas de frutos colhidos aos 60 e 70 DAA. Estes resultados permitem inferir que, em sementes imaturas (40 DAA), a organização das membranas celulares ainda era deficiente; com a permanência das sementes no fruto as membranas foram organizadas de modo a reduzir a lixiviação de solutos, conforme também constatado por Demir e Ellis (1992) e Dias et al. (2006a), em sementes de tomate.

Já sementes colhidas aos 60 e 70 DAA apresentavam, por ocasião da colheita, membranas bem estruturadas, de modo que o armazenamento pós-colheita do fruto não afetou o sistema de membranas e, consequentemente, a condutividade elétrica (Figura 1). Vidigal et al. (2006) observaram padrão similar de variação da condutividade elétrica em estudo sobre maturação de sementes de tomate.

Os perfis isoenzimáticos obtidos para sementes de pimenta em função da época de colheita e do armazenamento pós-colheita dos frutos (Figuras 2 a 5) revelaram, para a malato desidrogenase (MDH) (Figura 2), ausência de qualquer alteração no número e intensidade de bandas que pudesse ser associada ao estádio de maturação e à qualidade das sementes. A MDH desempenha papel significativo no ciclo de Krebs, uma vez que catalisa a conversão de malato a oxaloacetato, produzindo NADH, que é um produto fundamental na produção de ATP e de compostos intermediários essenciais ao funcionamento das células
(Taiz e Zeiger, 2004). Portanto, esta enzima poderia se constituir em eficiente marcador da respiração aeróbica das sementes durante a maturação. Embora não tenham ocorrido diferenças na atividade da MDH durante a maturação das sementes de pimenta, Taiz e Zeiger (2004) relatam que os órgãos de reserva em desenvolvimento necessitam de maior suprimento energético e com isso, a atividade respiratória nesses tecidos vegetais é mais intensa.

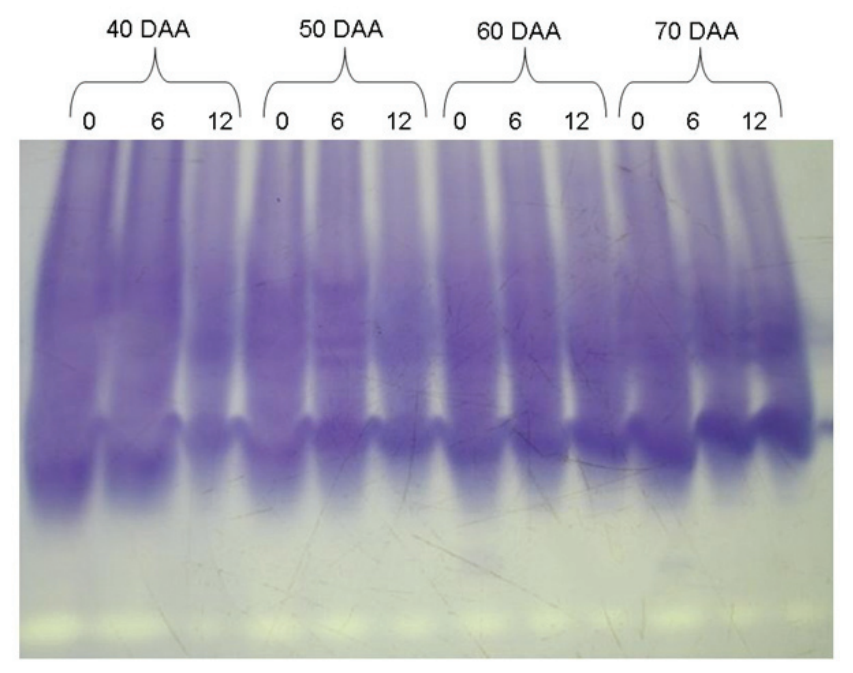

FIGURA 2. Padrões isoenzimáticos em sementes de pimenta extraídas de frutos colhidos aos 40, 50, 60 e 70 DAA e armazenados por 0 , 6 e 12 dias, revelados para a enzima malato desidrogenase (MDH).

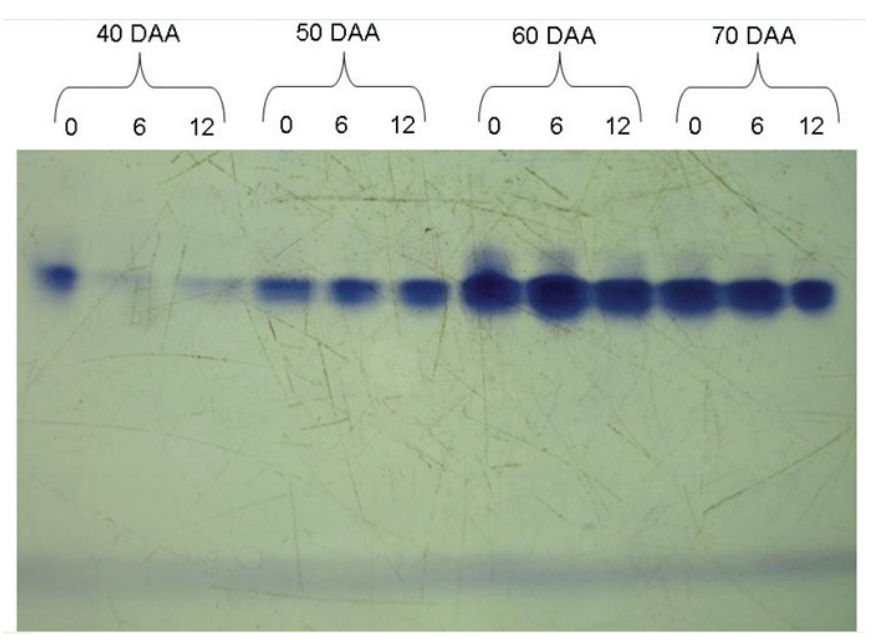

FIGURA 3. Padrões isoenzimáticos em sementes de pimenta extraídas de frutos colhidos aos 40, 50, 60 e 70 DAA e armazenados por 0 , 6 e 12 dias, revelados para a enzima álcool desidrogenase (ADH). 


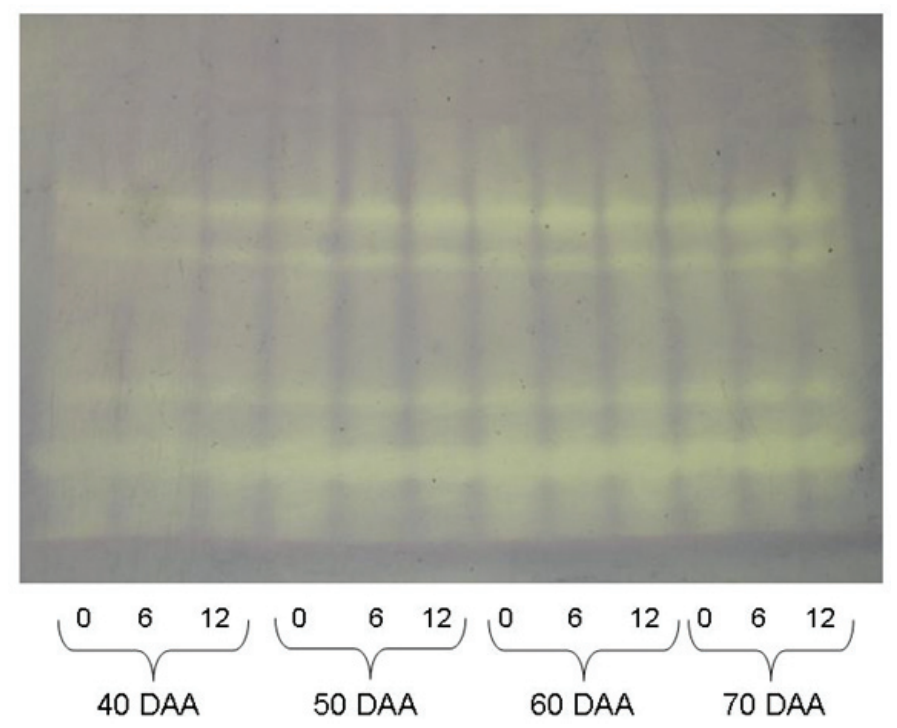

FIGURA 4. Padrões isoenzimáticos em sementes de pimenta extraídas de frutos colhidos aos 40 , 50, 60 e 70 DAA e armazenados por 0,6 e 12 dias, revelados para a enzima superóxido dismutase (SOD).

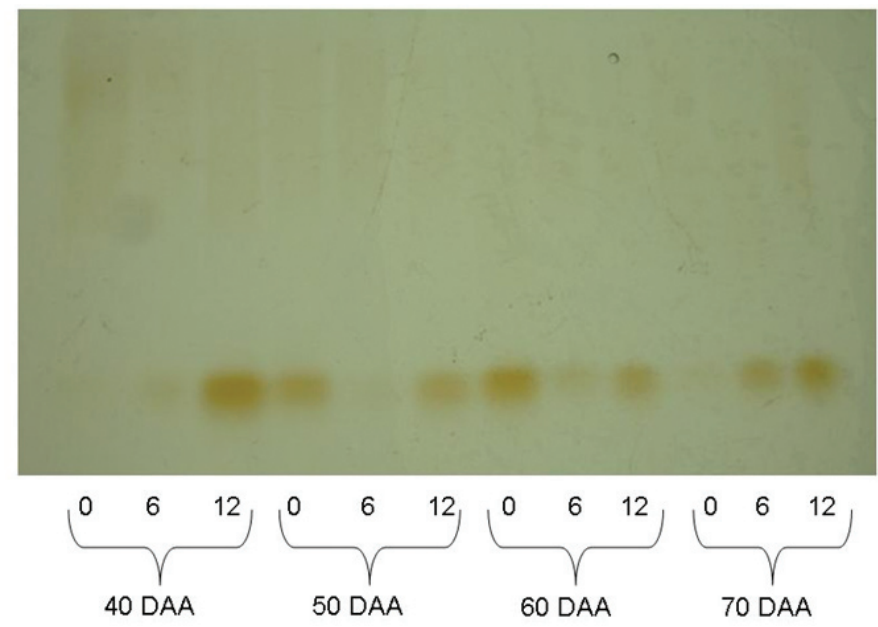

FIGURA 5. Padrões isoenzimáticos em sementes de pimenta extraídas de frutos colhidos aos 40, 50, 60 e 70 DAA e armazenados por 0, 6 e 12 dias, revelados para a enzima peroxidase (PO).

Por outro lado, para a enzima álcool desidrogenase - ADH (Figura 3) observa-se maior atividade nas sementes obtidas de frutos colhidos em estádios mais avançados de maturação
(60 e 70 DAA - frutos vermelhos), independentemente do período de armazenamento pós-colheita. Esta enzima está relacionada à respiração anaeróbica, promovendo redução do acetaldeído a etanol (Buchanan et al, 2005). O aceltadeído acelera a deterioração das sementes (Zhang et al., 1994); portanto, com o aumento da atividade da ADH, as sementes ficam mais protegidas contra a ação deletérica deste composto. Esses resultados são coincidentes com as alterações na qualidade fisiológica das sementes de pimenta observadas nos testes de germinação, primeira contagem, deterioração controlada e condutividade elétrica (Figura 1), indicando que a partir dos $60 \mathrm{DAA}$, independentemente do período de armazenamento dos frutos, ocorre à máxima qualidade das sementes. Padrão semelhante para a atividade da ADH foi encontrado por Brandão Jr. et al. (2002) em sementes de café, cujos frutos colhidos no estádio cereja (maduro) tiveram maior intensidade de bandas do que quando os frutos foram colhidos em estádio verde (imaturo); com isso, eles concluíram que a via fermentativa é fundamental para a manutenção da viabilidade de sementes de café após secagem.

Pelo zimograma da enzima superóxido dismutase - SOD (Figura 4), observa-se um pequeno aumento na intensidade das bandas nas sementes obtidas de frutos colhidos a partir de 50 DAA e armazenados por 6 dias. A SOD é a primeira enzima do grupo a trabalhar, atuando na linha de defesa contra formas reativas de oxigênio, uma vez que esta enzima anula a ação dos superóxidos $\left(\mathrm{O}_{2}^{-}\right)$, catalisando reações de transferência de dois elétrons para produzir peróxido de hidrogênio $\left(\mathrm{H}_{2} \mathrm{O}_{2}\right)$ (McDonald, 1999). Trabalhando com o desenvolvimento de sementes de soja, Silva (2006), observou que a atividade da SOD foi intensa durante todos os estádios de maturação avaliados.

O zimograma da enzima peroxidade - PO (Figura 5) não permite estabelecer associação entre atividade desta enzima e estádio de maturação de sementes de pimenta. A peroxidase desempenha um papel crítico no metabolismo das sementes, por utilizar peróxidos como aceptor de hidrogênio, podendo contribuir para o aumento dos mecanismos de defesa e prevenção de perda na qualidade (Ushimaru et al., 2001). De acordo com Bewley e Black (1994), a redução da atividade dessa enzima proporciona maior exposição dos sistemas de membranas aos efeitos do $\mathrm{O}_{2}$. Com isso, em decorrência do nível de danos das membranas, o oxigênio atua de forma mais intensa, promovendo oxidação dos compostos.

Em geral, sementes de alta qualidade fisiológica foram obtidas de frutos colhidos a partir de 60 DAA, com maiores valores de germinação e vigor, menores valores 
de condutividade elétrica e maior atividade de enzimas envolvidas na respiração e proteção contra radicais livres atuando nesse período.

\section{CONCLUSÕES}

Resultados superiores de germinação e vigor e maior atividade de enzimas, envolvidas na respiração e proteção contra radicais livres, são observados em sementes de pimenta obtidas de frutos colhidos a partir de $60 \mathrm{DAA}$, não sendo necessário o armazenamento destes após a colheita.

\section{REFERÊNCIAS}

ALFENAS, A. C. Eletroforese e marcadores bioquímicos em plantas e microrganismos. 2 ed. Viçosa: Editora UFV, 2006. 627p.

BARBEDO, C.J.; NAKAGAWA, J.; BARBEDO, A.S.C.; ZANIN, A.C.W. Influência da idade e do período de repouso pós-colheita de frutos de pepino $\mathrm{cv}$. Rubi na qualidade fisiológica de sementes. Horticultura Brasileira, v. 12, n. 2, p.118-124, 1994.

BEWLEY, J. D.; BLACK, M. Seed: physiology of development and germination. 2 ed. New York: Plenum Press, 1994. 445p.

BRANDÃO JR, D.S.; VIEIRA, M.G.G.C.; HILHORST, H.W.M. Aquisição da tolerância à dessecação nos diferentes estádios de desenvolvimento de sementes de cafeeiro (Coffea arábica L.). Ciência e Agrotecnologia, v.26, n.4, p.673$681,2002$.

BRASIL. Ministério da Agricultura e da Reforma Agrária. Regras para análise de sementes. Brasília, DF: SNDA/ DNDV/CLAV. 1992. 365p.

BUCHANAN, B.B.; GRUISSEM, W.; JONES, R.L. Biochemistry \& Molecular Biology of plants. Rockville: American Society of Plant Physiologists, 2005, 1367p.

CHAUHAN, K.P.S.; GOPINATHAN, M.C.; BABU, C.R. Electrophoretic variations of proteins and enzymes in relation to seed quality. Seed Science and Technology, v.13, p.629$641,1985$.

COPELAND, L.O.; McDONALD, M.B. Principles of seed science and technology. 4 ed. New York: Chapman \& Hall, 2001. 467p.

COSTA, C.J.; CARMONA, R.; NASCIMENTO, W.M. Idade e tempo de armazenamento de frutos e qualidade fisiológica de sementes de abóbora híbrida. Revista Brasileira de Sementes, v.28, n.1, p. 127-132, 2006.
DEMIR, I.; ELLIS, R.H. Changes in seed quality during seed development and maturation in tomato. Seed Science Research, v.2, p.81-87, 1992.

DIAS, D.C.F.S.; RIBEIRO, F.P.; DIAS, L.A.S.; SILVA, D.H.; VIDIGAL. D.S. Tomato seed quality in relation to fruit maturation and post-harvest storage. Seed Science and Technology, v. 34, n.3, p.691-699, 2006a.

DIAS, D.C.F.S.; RIBEIRO, F.P.; DIAS, L.A.S.; SILVA, D.J.H.; VIDIGAL, D.S. Maturação de sementes de tomate em função da ordem de frutificação na planta. Revista Ceres, v.53, n.308, p.446-456, 2006b.

FERGUSON, J.M.; TEKRONY, D.M.; EGLI, D.M. Changes during early soybean seed and axes deterioration: II. Lipids. Crop Science, v.30, n.1, p.179-182. 1990.

FILGUEIRA, F.A. Novo manual de olericultura: Agrotecnologia moderna na produção e comercialização de hortaliças. 2 ed. Viçosa: Editora UFV, 2005. 412p.

IBGE. Centro Demográfico. Resultados do universo relativo às características da população e dos domicílios. Rio de Janeiro, n.18, 1991.

INTENATIONAL SEED TESTING ASSOCIATION. Handbook of vigour test methods. 3. ed. Zürich, 1995. $117 \mathrm{p}$.

MARCOS FILHO, J. Fisiologia de semente de plantas cultivadas. Piracicaba: FEALQ, 2005. 495p.

McDONALD, M. B. Seed deterioration: physiology, repair and assessment. Seed Science and Technology, v.22, n.3, p.531-539, 1999.

NASCIMENTO, W.M.; DIAS, D.C.F.S.; FREITAS, R.A. Produção de sementes de pimentas. Informe agropecuário: Cultivo da pimenta, Belo Horizonte, v. 27, n.235, p.30-39, 2006.

OLIVEIRA, A.P.; GONÇALVES, C.P.; BRUNO, R.L.A.; ALVES, E.U. Maturação fisiológica de sementes de pimentão, em função de idade de frutos após a antese. Revista Brasileira de Sementes, v.21, n.2, p.88-94, 1999.

RIBEIRO, A.C.; GUIMARÃES, P.T.G.; ALVAREZ, V.H. Recomendações para o uso de corretivos e fertilizantes em Minas Gerais - 5 a aproximação. Viçosa: CFSEMG, 1999. $359 \mathrm{p}$.

SANCHEZ, V.M.; SUNDSTROM, G.N.; McCLURE, G.N.; LANG, N.S. Fruit maturity, storage and postharvest maturation treatments affect bell pepper (Capsicum annuиm L.) seed quality. Scientia Horticulturae, v.54, n.3, p.191201, 1993. 
SAS Institute. Statistical user's guide, version 6. 4.ed. Cary, NC: SAS Institute Inc, 1989. v.2, 846p.

SILVA, P.A. Estudo da qualidade fisiológica, bioquímica e ultra-estrutural durante o desenvolvimento e a secagem de sementes de soja. 2006. 55f. Tese (Doutorado em Fitotecnia) - Universidade Federal de Lavras, Lavras.

TAIZ, L.; ZEIGER, E. Fisiologia vegetal. 3.ed. Califórnia: Cummings, 2004. 719p.

USHIMARU, T.; KANEMATSU, S.; KATAYAMA, M.; TSUJI, H. Antioxicidative enzymes in seedlling of Nelumbo nucifera germinated under water. Physiologia Plantarum, v.112, n.1, p.39-46, 2001.
VIDIGAL，D.S.; DIAS, D.C.F.S.; NAVEIRA，D.S.P.; ROCHA, F.B.; BHERING, M.C. Qualidade fisiológica de sementes de tomate em função da idade e do armazenamento pós-colheita dos frutos. Revista Brasileira de Sementes, v.28, n.3, p.87-93, 2006.

VIDIGAL, D.S.; LIMA, J.S.; BHERING, M.C; DIAS, D.C.F.S. Teste de condutividade elétrica para sementes de pimenta. Revista Brasileira de Sementes, v.30, n.1, p.168174, 2008.

ZHANG, M.; MAEDA, Y.; FUTIHATA, Y.; NORAMURA, Y.I, ESASHI, Y. A machanism of seed deterioration in relation to volatile compounds evoked by dry seeds themselves. Seed Science Research, v.4, n.1, p.49-56, 1994. 